\title{
La protección de los derechos fundamentales por la justicia constitucional. Técnicas del control de constitucionalidad y la ponderación crítica
}

\section{The Protection of the Fundamental Rights by Constitutional Justice. Techniques of Constitutionality Control and Critical Ponderation}

\author{
Jaime Araujo Rentería *
}

Fecha de recepción: 17 de julio de 2008 Fecha de aprobación: 18 de septiembre de 2008

\section{Resumen}

El objeto de nuestra investigación es llamar la atención sobre lo que hay detrás de las técnicas del control de constitucionalidad que utilizan los guardianes de la constitución o los tribunales constitucionales y su gran carga ideológica-jurídica.

Detrás están cosmovisiones del mundo diferentes, así como puntos de partidas disímiles en la teoría del conocimiento, posiciones opuestas en la teoría del Derecho y premisas contrarias de la teoría de la interpretación jurídica y maneras distintas de concebir la interpretación constitucional.

Asimismo, se pretende llamar la atención sobre los irreconciliables puntos de partida filosófico-jurídicos que están detrás de la interpretación que hacen los tribunales constitucionales y que reflejan la eterna disputa entre lus positivismo y lus naturalismo. Metodológicamente, para demostrar este aserto se seguirán algunos lus filósofos que pueden servir de paradigma en el planteamiento del problema.

\section{Palabras clave}

Control de constitucionalidad, justicia constitucional, ius positivismo, ius naturalismo, juicio de proporcionalidad. 


\section{Abstract}

The objective of our investigation is to call for attention on what's behind the control techniques for constitutionality which are utilized by the guardians of the constitution or the constitutional courts and its ideological and juridical load.

Behind are the different world Cosmo-visions, as well as different starting points in the theory of knowledge, opposite positions in the theory of law and contrary premises of the theory of juridical interpretation and different ways to conceive the constitutional interpretation.

In the same way, it is pretended to call attention on the unfixable philosophical-juridical starting points that are behind the interpretation that constitutional tributes make and that reflect the eternal dispute between luspositivism and lusnaturalism. Methodologically, to demonstrate this assertion there's going to be following to lus philosophers that may serve as paradigm in the proposition of the problem.

\section{Key words}

Constitutionality control, constitutional justice, ius postitvism, ius naturalism, proportionality judgment.

\section{INTRODUCCIÓN}

\section{Teoría del conocimiento}

Desde el punto de vista de la teoría del conocimiento, la primera pregunta que hay que hacerse es la de si el hombre puede conocer o no los objetos que lo rodean o más exactamente puede conocer la verdad. Si la respuesta es negativa, la conclusión que se impone es que no pueden conocer tampoco las verdades jurídicas. Si la respuesta es positiva surge inmediatamente otra pregunta: ¿qué tipo de verdades conoce el hombre: verdades absolutas o verdades relativas? $\mathrm{Si}$ conoce verdades absolutas, es posible que haya una única respuesta correcta en el Derecho, pero si sólo conoce verdades relativas, es posible más de una respuesta correcta.

\section{Teoría del derecho}

La teoría del derecho refleja la sempiterna disputa entre lusnaturalismo y positivismo. Metodológicamente el positivismo separa el derecho de la moral; derecho y moral, a pesar de pertenecer ambas al mundo del deber ser, se deben mantener separados. Existe una diferencia entre objetivismo ético y el relativismo ético; entre valores objetivos y valores relativos. Mientras el lusnaturalismo presupone la existencia de valores objetivos y universales, el positivismo sostiene la relatividad de los valores y su reconducción a contextos culturales e históricos específicos.

La adopción por parte del positivismo del principio de no hacer juicios de valor se relaciona con dos exigencias fundamentales: no confundir el ser con el deber ser, a fin de evitar la falacia naturalista o ley de Hume; y la prohibición de confundir el estudio del Derecho con su valoración a la luz de criterios extrajurídicos.

El positivismo sólo acepta la existencia de "valores internos"; esto es, de aquéllos definidos por el propio creador de la constitución o la ley, pues si éste no los define, le deja al aplicador de la norma la posibilidad de llenarla con sus propios juicios de valor, que pueden variar de juez a juez; lo que crea inseguridad jurídica. Entre los juicios de valor 
internos y aquellos externos pasa la línea de confín entre ciencia del Derecho y política del Derecho.

\section{Teoría de la interpretación jurídica}

También en la teoría de la interpretación existe una diferencia radical entre positivismo y el lusnaturalismo. Para los primeros no existe una única interpretación de las normas jurídicas, sino que hay varias posibilidades de interpretación. Existe un marco de interpretación con varias posibilidades, todas ellas igualmente correctas. La decisión por una de ellas es ya no una decisión jurídica, sino política, en el exacto sentido del término; esto es, como posibilidad de escogencia entre varias alternativas igualmente legítimas. Para los positivistas el derecho tiene siempre un grado de indeterminación, que a veces es inconsciente (vaguedad, ambigüedad) y otras veces es buscada, a fin de lograr una mejor aplicación de la norma jurídica. Para el lusnaturalismo sólo hay una única respuesta correcta en el derecho.

\section{Teoría de la interpretación constitucional}

La teoría de la interpretación constitucional refleja -como conclusión que es- las premisas sobre las que se sustenta. La interpretación por valores (externos y extrajurídicos: morales) no es más que una modalidad del lusnaturalismo aplicado a la teoría de la interpretación constitucional. El positivismo acepta la existencia de valores, pero internos al Derecho.

Con estos elementos de juicio, se mirarán las particularidades de la interpretación constitucional y la gran carga ideológica que se esconde detrás de ella. Ideología entendida en su exacto significado: como un engaño o mentira que se hace por parte de los teóricos del Derecho y de los tribunales constitucionales a los ciudadanos.

\section{JUICIO DE PROPORCIONALIDAD O RAZONABILIDAD}

La técnica de control de constitucionalidad que se ha denominado juicio de proporcionalidad es distinta del test de igualdad. Este último es creación del constitucionalismo norteamericano, mientras que el primero es del constitucionalismo europeo. El control de constitucionalidad por medio del principio de proporcionalidad (o racionalidad) es una relación entre medios y fines; ahora bien, lo primero que se debe precisar es que éste sólo se aplica a las acciones de los poderes públicos y no a las acciones entre particulares, que no se deben someter al principio de proporcionalidad.

Con respecto al fin, hay que señalar que cada acción estatal tiene que perseguir un fin legítimo y éste debe tener ciertas características, entre otras, no estar prohibido, ya que si la Constitución tiene un fin prohibido la ley que lo persigue es inconstitucional. El fin debe estar entonces permitido. Además, debe ser un fin constitucionalmente permitido y relevante. Es preciso aclarar que el Estado no tiene un único fin, sino pluralidad de fines.

El medio utilizado (la ley que se somete al control de constitucionalidad) tampoco debe estar prohibido; por ejemplo, si el fin es la búsqueda de la verdad dentro de los procesos, un medio como la tortura está prohibido en el Estado de derecho, y si una ley permite la tortura del sindicado debe ser declarada inconstitucional. Además de estar permitido, el medio debe ser adecuado para lograr el fin que se persigue. Este requisito apunta a la idoneidad del medio utilizado; si éste no lleva al fin que se persigue, porque es inocuo o no es idóneo, la norma debe ser declarada inconstitucional, pues no sirve para aquello que se persigue.

La Constitución trata de erigirse en una valla para quien desee perseguir sus fines (justos o injustos) por medios que 
la comunidad ha juzgado históricamente peligrosos o que afecten intereses dotados de consenso. Por esto ha sido tan común en nuestra historia que diversos grupos hayan tratado de eliminarla, suspenderla, sustituirla 0 , más modestamente, utilizar sus resquicios.

Cada individuo persigue lo que entiende como sus propios fines por los medios que juzga conducentes. Pero en esa persecución hay vías que le está vedado recorrer: no puede resolver sus problemas sentimentales matando a su cónyuge, ni agregar una habitación a su vivienda invadiendo la del vecino, ni incrementar la rentabilidad de su negocio omitiendo el pago de impuestos o abonando salarios inferiores a los establecidos, ni asegurarse el respeto y la obediencia de sus hijos mediante mutilaciones o castigos crueles, ni divertirse en sus fiestas causando ruidos molestos, ni llegar puntualmente a sus compromisos estacionando el automóvil en doble hilera. Todos esos fines son lícitos, pero sólo pueden perseguirse por medios no prohibidos, cualquiera sea el juicio del interesado acerca de la mayor eficacia de alguno de los medios vedados respecto de los permitidos. Las restricciones se imponen por una vía ajena a la ética, porque no es posible confiar, no ya en la fuerza de voluntad de los infractores potenciales (en especial frente a balances valorativos coyunturales e individuales opuestos a la restricción), sino incluso en el acuerdo unánime respecto de la inconveniencia de tales medios (Guibourg, 1992).

El medio, además de no estar prohibido y ser idóneo, debe ser necesario, de tal manera que si es idóneo, pero no necesario, la norma debe ser declarada inconstitucional. El concepto de necesidad es muy importante, ya que si existe otro medio alternativo que permita lograr el mismo fin con una menor restricción o limitación del derecho fundamental y el legislador no lo emplea, la norma debe ser declarada inconstitucional. Como se ve, el concepto de necesidad (medio necesario) es muy importante en el control de constitucionalidad para salvaguardar los derechos fundamentales, por cuanto la ley está restringiendo o limitando un derecho de un ciudadano y la regla general es que los ciudadanos disfruten plenamente de sus derechos, sin restricciones, sin límites, sin cortapisas. De modo que si existe otra restricción menos gravosa del derecho, el legislador debe acudir necesariamente a la menos gravosa y si escoge la más grave, la más restrictiva, la norma debe ser declarada inconstitucional.

En consecuencia, en el control de constitucionalidad con el principio de proporcionalidad el medio no puede estar prohibido, debe estar permitido, ser adecuado y además necesario, pues si el control llega sólo hasta el elemento adecuado es un control de constitucionalidad deficiente, que permite que se vulneren los derechos fundamentales de los ciudadanos.

Finalmente, este método de control de constitucionalidad tiene la denominada proporcionalidad en sentido estricto, que en términos económicos sería una relación costo-beneficio, dado que si el costo es mayor que el beneficio, la norma debe ser declarada inconstitucional.

Este tema esta íntimamente ligado con el de la máxima realización de los derechos fundamentales. Los derechos fundamentales exigen su máxima realización posible, o lo que es lo mismo, está prohibida su protección deficiente, de modo que en caso de conflicto entre principios se deben mirar la relación costo-beneficios, pues si un derecho se realiza como un medio en un grado mayor que otro, pero afecta con mayor intensidad otro derecho, puede no ser el adecuado; en cambio, si otro medio que realiza menos un derecho afecta de una manera menor los bienes y derechos que juegan en sentido contrario, el más adecuado. Por ejemplo, si con el medio A se realiza un derecho en un $95 \%$, pero afecta a otro derecho en un $90 \%$, y el medio B realiza un derecho en un $85 \%$, pero afecta al derecho que juega en un sentido con- 
trario sólo en un $10 \%$, será preferible este último medio en vez del primero, pues tiene una mejor relación costo beneficio.

Dicho de otra manera, la norma sólo está ajustada a la Constitución si el beneficio que recibe la sociedad es mayor que el costo de haber restringido o limitado un derecho fundamental. En primer lugar, el Tribunal Constitucional debe preguntarse cuál es la importancia del fin que el Estado persigue con su intervención; en segundo lugar, cuál es la importancia del derecho fundamental que se limita por medio de la ley. Después de comparar los dos derechos en conflicto y de determinar que el que se limita es menor que el que se protege con el fin perseguido, se puede declarar que la limitación del Derecho se ajusta a la Constitución.

Como se observa, el control de constitucionalidad por medio del principio de proporcionalidad exige que se cumplan todos los elementos anteriormente analizados, de forma que si falta alguno de ellos, la ley debe ser declarada inconstitucional.

\section{Acerca de la razonabilidad}

En muchas ocasiones, se modifica el juicio de proporcionalidad y se habla de juicio de razonabilidad. Pero ¿qué se quiere decir con este concepto? Lo primero que se debe señalar es que se refiere a la interdicción o prohibición de arbitrariedad. Lo segundo, que busca analizar si la distinción que hizo el legislador está justificada o no.

Existe una diferenciación arbitraria "cuando para la diferenciación legal no es posible encontrar una razón razonable, que surja de la naturaleza de la cosa o que, de alguna forma, sea concretamente comprensible". Por lo tanto, una diferenciación es arbitraria y por ello está prohibida, cuando no es posible encontrar una razón calificada de una determinada manera. La calificación de esta razón es descrita de múltiples maneras. En la cita que se acaba de presentar se exige que se trate de una razón razonable o que surja de la naturaleza de la cosa o que, de alguna otra manera, sea concretamente comprensible. En otras formulaciones se exige que la falta de objetividad de la razón de la diferenciación no sea evidente, y, en otras, simplemente que la razón haga que la diferenciación esté justificada. El trasfondo de estas fórmulas está constituido por el postulado de una forma de consideración orientada por la idea de la justicia.

De todo esto se infiere que tiene que haber una razón suficiente para las justificaciones y que la cualificación de la razón como suficiente es un problema de valoración. En este caso, el interés sólo debe recaer en lo primero: para la admisibilidad de las diferenciaciones tiene que haber una razón suficiente que las justifique; esto significa que cuando no existe una razón tal, está ordenada la igualdad de tratamiento. Esto se puede formular con el siguiente enunciado, que constituye una precisión de la versión débil de la máxima general de igualdad propiciada más arriba: "Si no hay ninguna razón suficiente para la permisión de un tratamiento desigual, entonces está ordenado un tratamiento igual" (Alexy, 1997, p. 395).

En abstracto, el examen de razonabilidad puede descomponerse en dos patrones diferenciados: por un lado, el de la constitucionalidad de la finalidad pretendida por la norma y, por otro, el de la adecuación entre la distinción establecida por la norma y la finalidad de ésta. El legislador es libre de perseguir cualesquiera finalidades, siempre que sean lícitas en el marco constitucional.

Si lo anterior es cierto, el examen exigido por el principio genérico de igualdad en la ley puede reducirse a la exigencia de adecuación suficiente entre la clasificación empleada y la finalidad de la norma, que es en lo que en realidad ha consistido el análisis jurisprudencial de la razonabilidad de las distinciones consideradas. Ahora bien, en realidad, si esta relación entre medios y fines pudiera y debiera ser perfecta, el examen de razonabilidad se convertiría en un ejercicio 
técnico, básicamente objetivable en los términos de las ciencias sociales y que se podría reducir sin más a una aplicación de lo que Max Weber denominó racionalidad instrumental. Pero si, por un lado, la existencia de una relación de igualdad relevante entre dos o más individuos presupone una atribución valorativa $y$, por otro lado, la adecuación entre fines y medios normativos, particularmente en cuanto afecta al principio genérico de igualdad ante la ley, no siempre necesita ser estricta o exacta para ser calificada como razonable, entonces el examen de razonabilidad no puede reducirse al de racionalidad, lo que deja abierto el campo a la introducción de juicios de valor en la determinación de la propia relación de adecuación. Veámoslo por partes.

En efecto, por un lado, ninguna relación de igualdad, especialmente en contextos sociales, éticos y jurídico-políticos, es propiamente de identidad, por lo que la determinación de aquélla [que] supone necesariamente la existencia de ciertos rasgos comunes y ciertos rasgos disímiles, de los que se destacan los primeros como relevantes en función de un determinado aspecto o trato. Esto significa que la simple predicación de una determinada relación de igualdad entre dos o más personas, incluso en contextos descriptivos, exige evaluar y seleccionar los rasgos que se consideran relevantes en uno u otro aspecto. Además, en las relaciones de igualdad prescriptivas, esto es, cuando la relevancia de la igualdad se determina en función de un determinado trato que se propone como debido o prohibido, la propia conexión entre los rasgos considerados comunes y el trato asociado a su posesión depende a su vez de una valoración de carácter práctico $y$, en último término, ético. Tal conexión, así pues, no puede comprobarse empíricamente, al modo de la racionalidad instrumental, sino que, en el mejor de los casos, supone un juicio de razonabilidad, en el que se aportan argumentos capaces de recibir mayor o menor adhesión en un determinado contexto histórico-social (Ruiz, 1992).

\section{ACERCA DEL CONCEPTO DE RAZÓN SUFICIENTE. PRECISIÓN LÓGICA}

En la cita de Robert Alexy que se hizo anteriormente y en la jurisprudencia europea, americana y colombiana, cuando se avoca el control de constitucionalidad de una norma, con frecuencia, se dice que existe una razón suficiente para su existencia o expedición -o, más exactamente, para la diferenciación que establece- y que, en consecuencia, está ajustada a la Constitución. La lógica o ciencia del pensar correctamente tiene cuatro principios fundamentales: identidad, no contradicción, tercero excluido y razón suficiente. Los tres primeros los "descubrió" o sistematizó Aristóteles y el cuarto es creación de Leibniz.

En relación con la pregunta de cuál es el fundamento de algo o qué hace que una cosa sea de cierta manera y no de otra ( $i q u e ́$ hace que el perro sea perro y no gato?, ¿cuál es la razón de que el hombre sea hombre y no elefante, mico u otro ser de la naturaleza?), se acudía al concepto de razón suficiente, que en ese contexto fue utilizado por Aristóteles y todos los filósofos, hasta que Leibniz cambió el significado del concepto y, de paso, modificó los principios lógicos.

Ya se ha señalado que mientras para el Derecho la cuestión es de validez o invalidez de la norma jurídica, para la lógica es de verdad o falsedad del juicio. Desde Aristóteles hasta Leibniz, la lógica sólo tenía una categoría de verdad: la verdad necesaria. Leibniz introdujo al lado de esta otra verdad, la verdad contingente. Ahora bien, es el principio de la razón suficiente lo que explica las verdades contingentes. Veamos cómo fue la evolución.

En primer lugar, la causa, en el sentido de razón de ser. Éste es uno de los principales significados del término causay es justo aquél por el que contiene la explicación y la justificación racional de la cosa de la cual es causa. Aristóteles dice: 
Creemos conocer absolutamente un objeto en particular -o sea, no accidentalmente o de modo sofista- cuando creemos conocer la causa por la cual la cosa es, conocer que ella es causa de la cosa y que, por lo tanto, ésta no puede ser de otra manera (Analíticos posteriores,1.2. 71B 8).

En este sentido, la causa es razón, logos (De part. An.,1,1 639b 15), ya que hace comprender no solamente el acaecer de hecho de la cosa, sino también su no poder ser de otra manera, esto es, su necesidad racional. Por lo tanto, en la doctrina aristotélica, como en las que dependen de ella, la causa-razón es un concepto ontológico que expresa la necesidad propia del ser en cuanto sustancia. Hegel adopta el concepto en este mismo sentido: "El Fundamento (F.) es la esencia que es en sí y ésta es esencialmente F., y F. es sólo en cuanto fundamento de algo, de un otro" (Ene., \&121). En efecto, en este sentido el F. es "la esencia puesta como totalidad" (Hegel, Ene., \&121), es decir, la razón de la necesidad de una cosa, como lo consideraba Aristóteles.

No obstante, por obra de Leibniz, la noción adquirió un significado distinto y específico, por el que se distingue nítidamente del de causa esencial o sustancia necesaria. Es decir, pasa a designar una relación privada de necesidad, la que da a entender o justifica la cosa; el principio de esta relación es denominado principio de razón suficiente (principium rationis sufficientis). Leibniz llega a la formulación de este principio a través de la oposición entre la relación libre, pero determinante y la relación necesaria. Asimismo, dice que la relación o concatenación es de dos especies: una es absolutamente necesaria, de manera tal que su contrario implica contradicción y tal relación se verifica en las verdades eternas, como son las de la geometría. La segunda no es necesaria, sino que es ex hypothesi y, por así decirlo, por accidente, y es contingente en sí misma, ya que su contrario no implica contradicción.
Esta segunda conexión se verifica en la relación entre una sustancia individual y sus acciones; por ejemplo, el fundamento del hecho de que César pasara el Rubicón se encuentra indudablemente en la naturaleza misma de César, pero ello no dice que el hecho fuera necesario en sí mismo y que su contrario implique contradicción. Del mismo modo, Dios elige siempre lo mejor, pero lo elige libremente y lo contrario de lo que elige no implica contradicción.

Toda verdad fundada en este tipo de decretos es contingente, aun siendo cierta, porque, en efecto, estos decretos no cambian la posibilidad de las cosas, y aunque Dios -como se ha dicho- elija siempre indudablemente lo mejor, esto no impide que lo que es menos perfecto no sea y no permanezca posible en sí mismo, si bien no sucede, dado que no es su imposibilidad lo que lo hace rechazar, sino su imperfección. Ahora bien, nada cuyo opuesto sea posible, es necesario (Leibniz, discours de metaphysique, 1686, \& 13).

Como es evidente a través de estos textos de Leibniz, el F. o razón suficiente tiene una capacidad explicativa diferente de la causa o razón de ser de Aristóteles. Esta última, en efecto, explica la necesidad de las cosas, el porqué de que la cosa no pueda ser de otra manera que como es. El fundamento o razón suficiente explica la posibilidad de la cosa, esto es, explica por qué la cosa puede ser o comportarse de determinada manera. Precisamente, por esta razón, Leibniz consideró el principio de razón suficiente como fundamento de las verdades contingentes y continuó admitiendo, como ya lo había hecho Aristóteles, el principio de no contradicción como base de las verdades necesarias (Abbagnano, 1995, pp. 578-579).

Se puede concluir que el principio de razón suficiente creado por Leibniz hace referencia a verdades contingentes o no necesarias y no a verdades necesarias, que se basan en otro principio 
que es el de no contradicción. Si, por otro lado, se recuerda que el control de constitucionalidad debe verificar que el medio empleado (la ley que distingue) sea necesario, ya que si existe otro medio menos gravoso hay que utilizarlo, no se comprende por qué se habla de que existe una razón suficiente. Cuando se habla de razón suficiente lo que se quiere decir, en realidad, es que ese medio no es necesario y si no es necesario debe ser declarado inconstitucional.

\section{SOBRE EL TEST DE IGUALDAD}

Este test, creación del constitucionalismo norteamericano, se puede sintetizar así:

Según la reconstrucción propuesta por Gerald Gunther tal jurisprudencia puede sistematizarse en tres tipos de test: (a) un test estricto -denominado Strict Scrutiny-, para las distinciones normativas que afectan a derechos fundamentales o son "sospechosas" (esto es, utilizan la raza 0 , con menos rotundidad, la filiación ilegítima conforme al cual los fines de la norma o medida deben ser "perentorios" (compelling) y la distinción "necesaria" (necessary) para la realización de tales fines (b) un test mínimo -denominado Mínimum Rationality Requirement o Rational Basis Test-, utilizado en principio para la generalidad de las distinciones normativas, que exige únicamente que los fines sean "lícitos" (legitimate) en el marco de alguna concepción del interés general y que la distinción esté "racionalmente relacionada" (rationaily related) con ellos; y, en fin, (c) un test intermedio -llamado Intermediate Review-, que se ha ido abriendo paso entre los dos anteriores para las distinciones que utilizan categorías "sensibles" (aunque no "sospechosas"), como el sexo, la discapacitación o la edad, y por el que se exige que el fin de la norma o medida sea "importante" (important) y que la distinción esté "sustancialmente relacionada" (substantially related) con tal fin. En la anterior tripartición, es claro que la mayor o menor exigencia en la relación entre la distinción normativa y su finalidad corresponde con la mayor o menor tolerancia hacia la infra o suprainclusividad de la norma en cuestión (Ruiz, 1992, p. 62).

Un excursus histórico por la interpretación constitucional norteamericana muestra cómo surgieron ciertas teorías para resolver algunos problemas prácticos propios de su sistema jurídico y cómo las utilizan en Colombia en un contexto social y jurídico diverso, sin saber de dónde vienen y qué fin o interés perseguían, a quiénes perjudicaban o beneficiaban. Mientras no se tenga conciencia de su origen o finalidad no se sabrá distinguir la gran carga ideológica que se esconde detrás de ellas.

Para acercarse a la historia constitucional de Estados Unidos se seguirá en lo fundamental a Christopher Wolfe, especialmente obra La transformación de la interpretación constitucional. El denominado test de igualdad surgió para resolver un problema práctico en el constitucionalismo norteamericano, fundamentalmente por el conflicto surgido entre el presidente Roosevelt y la Corte Suprema de Estados Unidos. El presidente norteamericano se quejaba de que la Corte Suprema le declaraba inconstitucionales sus leyes de contenido económico, esto le impedía aplicar su programa económico, lo que le generó un gran conflicto con esa Corte, además que dividió la opinión pública norteamericana.

Como los magistrados de la Corte Suprema de los Estados Unidos son nombrados por el presidente de la República, Roosevelt logró hacer una mayoría en la Corte Suprema. Ese tribunal cambió la jurisprudencia de la Corte Suprema, para decir que el control de constitucionalidad sobre temas económicos de ahora en adelante iba a ser más flexible y que abandonaba el control estricto que había hecho para dejar que el gobierno y el Congreso hicieran las leyes económicas como quisieran, pues lo único que exigiría en el futuro sería un mínimo de racionalidad en la ley. Con este cambio de jurisprudencia de la Corte Suprema, el gobierno de Roosevelt logró lo que quería, que era atenuar y debilitar el control de constitucionalidad 
sobre sus leyes económicas, y lógicamente esta tesis benefició al poder ejecutivo y restringió el control de constitucionalidad.

Éste es el origen histórico de los diferentes tests en el control de constitucionalidad, y no hay duda de que surgió para beneficiar al gobierno, con el riesgo de afectar derechos económicos de los ciudadanos. Toda ley tiene un mínimo de racionalidad, pues no habría sido expedida si fuera un absurdo total, y muchas leyes violan derechos de los ciudadanos, pero, al aplicarles un test débil, el tribunal constitucional termina avalándolas en detrimento de los derechos fundamentales.

En los años sesenta, el Tribunal cambió su política posterior a 1937, a fin de emplear la cláusula de la igual protección como instrumento de sus reformas igualitarias; naturalmente, la redistribución se basaba en dicha cláusula. Por lo tanto, a mediados de esta década, el Tribunal desarrolló una interpretación a dos niveles, en cuanto a la igual protección. Fue en el nivel inferior, aplicable sobre todo a la regulación económica, en el cual el Tribunal tenía sólo que demostrar que su clasificación era "racional". Después había un nivel superior, en el cual la clasificación estatal estaba sometida al "estricto escrutinio" y sólo se podía justificar a partir del "interés estatal irrenunciable". Este nivel superior tenía dos ramas: en primer lugar, había algunas "clases sospechosas", cuyo ejemplo clásico era la raza; y en segundo lugar, había determinados "derechos fundamentales", cuyo mejor ejemplo era la igualdad en el derecho al voto.

Sin embargo, el cambio en la composición de la Corte Suprema y especialmente por la designación que de nuevos jueces hicieron los presidentes del partido Republicano llevó a que el Tribunal Burguer modificara los tests del control de constitucionalidad (débil y estricto) e introdujera el test intermedio, especialmente, diversos niveles de control. Veamos cómo fue el proceso.
El fallo de Powell rechazó el análisis de los "derechos fundamentales", porque la igualdad en la educación no es un derecho constitucionalmente garantizado. Un derecho es fundamental no por su importancia social, sino porque está explícita o implícitamente garantizado por la Constitución. El hecho de que sea necesaria cierta educación para tener acceso efectivo al derecho a la libertad de expresión o al derecho al voto puede apoyar la demanda de un mínimo de educación -demanda no realizada en este caso-, pero no una demanda de igualdad educativa. Por otro lado, la ley de Texas había contribuido mucho a hacer que los gastos educativos del distrito fueran más iguales, por lo que se legisló ayuda suplementaria estatal que beneficiaba de forma desproporcionada a los distritos más pobres. Dada la razón de que la financiación local ayuda a proteger el control local, Texas podía libremente emplear este sistema financiero.

La opinión de Marshall en desacuerdo contenía algunas observaciones cáusticas. Mientras que algunos de los derechos fundamentales en anteriores casos de igual protección estaban garantizados por la Constitución (por ejemplo, el implícito de rechazo constitucional a viajar, en Shapiro versus Thompson), Marshall preguntaba si la Constitución garantizaba el derecho a procrear, el derecho a votar en las elecciones estatales, o el derecho a apelar por una condena. Repitió su sugerencia de Drandridge, que consistía en que el Tribunal adoptara una norma de "escala móvil" para sustituir el "enfoque rígido" de la norma de dos niveles; es decir, en lugar de clasificar los casos en una o dos categorías rígidas -una con un control extremadamente estricto, otra con un control extremadamente deferente-, el Tribunal debía reconocer una escala de derechos -desde el menos importante subiendo gradualmente hasta el más importante a través de diferentes niveles- $y$ varias la severidad del control, según la importancia del derecho. 
En ciertos aspectos, la sugerencia tenía bastante sentido, una vez que el Tribunal hubiera decidido elevar ciertos derechos y darles una protección especial; a esta práctica la mayoría se negó a renunciar. Al mismo tiempo, es difícil resistir a la tentación de creer que la conversión de Marshall a un enfoque "más flexible" se hubiera producido en 1971, más que en 1968 a causa de su especulación, en cuanto al futuro del Tribunal. Si el Tribunal Warren hubiera seguido a todo vapor en los años setenta, sumando sin cesar nuevos derechos al "estricto escrutinio", ihubiera criticado Marshall la "rigidez" de su en foque? O ifue su conversión a la flexibilidad tan sólo un reconocimiento de que con el Tribunal Burger media tajada era mejor que nada?

En 1972 también surgió un deseo de un nivel intermedio, más fuerte que la mera racionalidad, pero menor que el estricto escrutinio; se trataba de un caso que derogó una ley de Massachusetts que prohibía la distribución de contraceptivos a los menores solteros, $\mathrm{o}$ a las parejas casadas a no ser que fuera a través de un farmacéutico o de un médico, y en el curso incierto de las decisiones sobre leyes referidas a hijos ilegítimos.

La norma intermedia ha proporcionado al Tribunal un marco para examinar un número mayor de leyes con mayor atención. Si el estricto escrutinio suponía una opinión más restringida de los poderes legislativos, dado que dicho escrutinio era generalmente "fatal de hecho" -cualquiera sea el significado de la posibilidad teórica de demostrar un interés estatal obligatorio y estrechamente cortado-, la misma severidad impuso un tipo de disciplina al Tribunal -una duda en cuanto a ampliar mucho la categoría.

Con el escrutinio intermedio, el Tribunal se sentía libre para examinar más leyes cuidadosamente, sabiendo que las menores demandas de este escrutinio le permitirían apoyar muchas de las leyes así examinadas. No obstante, la evaluación de si un interés del gobierno era "importante" y si la ley favorecía "esencialmente" esos intereses dejó necesariamente al Tribunal en un marasmo de juicios subjetivos. Como argumentó Burger, en su desacuerdo (Plyler versus Doe, 1982), el Tribunal podía remendar "retazos de lo que se podía clasificar de categoría cuasi sospechosa y análisis de derechos cuasi fundamentales" y prolongar "una teoría cortada por la costumbre sobre los hechos" de un caso. El resultado es una orientación simplemente burda, la cual, a su vez, es sencillamente un régimen por decreto arbitrario, y no una operación de gobierno en virtud y a través del principio de derecho. Quizá algunas personas hayan agradecido al Tribunal Burger que sus decretos sean con frecuencia más moderados de lo que fueron los del Tribunal Warren. Incluso si esto es cierto, a duras penas justificaríael principio de tal norma [OXP1].

Las diferencias que el Tribunal Supremo estadounidense ha ido desarrollando a lo largo del tiempo en el examen o test utilizado han tenido como objeto analizar las alegaciones de violación de la cláusula de "la igual protección de las leyes" garantizada por la Enmienda XIV. Según la reconstrucción propuesta por Gerald Gunther, tal jurisprudencia se puede sistematizar en tres tipos de tests:

- Un test estricto -denominado Strict Scrutiny-, para las distinciones normativas que afectan los derechos fundamentales o son "sospechosas"; esto es, utilizan la raza o, con menos rotundidad, la filiación ilegítima conforme al cual los fines de la norma o medida deben ser "perentorios" (compelling) y la distinción "necesaria" (necessary) para la realización de tales fines.

- Un test mínimo -denominado Mínimum Rationality Requirement o Rational Basis Test-: es utilizado en principio para la generalidad de las distinciones normativas, que exige únicamente que los fines sean "lícitos" (legitimate) en el marco de alguna concepción del interés 
general y que la distinción esté "racionalmente relacionada" ( rationaily related) con ellos.

- Un test intermedio (Intermediate Review), que se ha ido abriendo paso entre los dos anteriores para las distinciones que utilizan categorías "sensibles" (aunque no "sospechosas"), como el sexo, la discapacidad o la edad, y por el cual se exige que el fin de la norma o medida sea "importante" (important) y que la distinción esté "sustancialmente relacionada" (substantially related) con tal fin.

En la tripartición anterior es claro que la mayor o menor exigencia en la relación entre la distinción normativa y su finalidad corresponde con la mayor o menor tolerancia hacia la infra o suprainclusividad de la norma en cuestión (Ruiz, 1992, p. 62).

\section{Síntesis}

La evolución del control de constitucionalidad en Estados Unidos permite llegar a las siguientes conclusiones:

- Debido al conflicto con el presidente Rooselvelt, un control estricto pasó a dos niveles, pues se creó un nivel débil para controlar la legislación económica, en la cual sólo se exigía que la norma fuera racional. El control estricto se aplicaba a las categorías sospechosas (raza, etcétera) y a los derechos fundamentales ${ }^{1}$.

1 "Tampoco discuto mucha doctrina jurídica técnica, excepto cuando es absolutamente necesario. Cada parte del derecho, incluido el derecho constitucional, hace uso de mecanismos y categorías especiales inventados en un intento de disciplinar principios jurídicos abstractos con un vocabulario técnico. Sin embargo, los principios resisten tal disciplina, y los aparatos tienen una vida de estantería finita -con frecuencia muy corta. Cada uno comienza con una estrategia útil y modesta al demostrar las implicaciones de principios generales para un conjunto limitado de problemas. Pero algunos desarrollan una vida y fuerza propias, y se convierten en tiranos que envejecen, cuyas malas rachas y cuidados generan más desgracias que dichas, hasta que son finalmente desechados -sin dientes, sin nada- por un juez creativo con nuevos ardides. Por ejemplo, los estándares de niveles 'estricto', 'relajado' e 'intermedio' de 'escrutinio', que la Corte Suprema ha usado por décadas en sus decisiones de protección, quizá alguna vez sirvieron a un propósito útil al ofrecer presunciones
- El Tribunal Burguer redujo los miembros integrantes de la categoría sospechosa y los derechos fundamentales y que creó una categoría intermedia, test medio que en realidad son diversos test intermedios.

- En realidad, actualmente, el control de constitucionalidad se ha relajado contra los derechos de los ciudadanos y esto ha permitido a los gobiernos mantener una serie de leyes que con un control estricto deberían ser declaradas inconstitucionales y que han vulnerado derechos fundamentales del pueblo norteamericano.

\section{LA PONDERACIÓN DE LOS PRINCIPIOS CONSTITUCIONALES. RICCARDO GUASTINI $^{2}$}

"Puede suceder (ciertamente, ocurre a menudo) que dos principios - al igual que acontece con las normas- entren en conflicto. Más aún, algunos entienden que es un rasgo definitorio de los principios el que cada uno de ellos se encuentre en conflicto con otros, de manera que, dado un supuesto de hecho al que sea de aplicación un principio $\mathrm{P} 1$, hay siempre al menos otro principio $\mathrm{P} 2$ igualmente aplicable al mismo supuesto de hecho e incompatible con P1. Incompatible, en el sentido de que la aplicación de P2 llevaría a resultados diversos de la aplicación de P1.

Ahora bien, los conflictos entre principios -ejemplo paradigmático: los conflictos entre principios constitucionales (sobre los que se centra lo que sigue)- presentan generalmente (no siempre $y$, por tanto, no necesariamente) tres características que merecen ser reseñadas.

\footnotetext{
funcionales acerca de las discriminaciones que indican o no fallas a la preocupación igual. Pero ya no lo hacen más. Este libro niega que tales artificios doctrinales se concentren en los principios fundamentales a los que se supone sirven" (Ronald, s.f., p. 47).

2 Basado en: Principios de derecho y discrecionalidad judicial, de Ricardo Guasttini.
} 
1. En primer lugar, los conflictos entre principios -en particular, entre principios constitucionales- son antinomias entre normas coetáneas y de idéntico rango en la jerarquía de fuentes.

2. En segundo lugar, Ios conflictos entre principios son, por lo general, antinomias en concreto. Este punto requiere alguna explicación.

Se da una antinomia en abstracto (o necesaria) cada vez que dos normas conectan consecuencias jurídicas incompatibles con supuestos de hecho abstractos, es decir, con clases de supuestos de hecho (concretos) que se superponen (en todo o en parte) conceptualmente. De esta suerte, la antinomia puede ser identificada ya en el plano de la interpretación textual, en abstracto, es decir, sin que sea necesario representarse un supuesto de hecho concreto. Si, por ejemplo, una primera norma prohíbe el aborto y una segunda norma permite el aborto terapéutico, la antinomia puede ser reconocida en abstracto, con independencia de cualquier supuesto concreto, desde el momento en que la clase de los abortos terapéuticos está conceptualmente incluida en la clase de los abortos sin especificaciones.

Por el contrario, se da una antinomia en concreto (o contingente) cuando en el momento de la aplicación dos normas conectan consecuencias jurídicas incompatibles a un mismo supuesto fáctico concreto. Esto ocurre cada vez que un supuesto de hecho concreto (o una subclase de supuestos de hecho concretos) recae simultáneamente en dos clases de supuestos de hecho diversos y no relacionados conceptualmente para los que el derecho prevé consecuencias jurídicas incompatibles. De este modo, la antinomia puede ser identificada sólo en sede de aplicación de las normas al caso concreto (al que, precisamente, se dé la circunstancia de que ambas sean aplicables). Imaginemos que una primera norma disponga: "Los ciudadanos deben pagar los impuestos" y una segunda norma disponga: "Los desempleados no deben pagar ningún impuesto". Los supuestos de hecho abstractos a que las dos normas se refieren -respectivamente, ciudadanos y desempleados- carecen de relación desde el punto de vista conceptual, pues que existan o no de hecho ciudadanos sin empleo es algo contingente. Por tanto, el conflicto entre las dos normas en cuestión no es necesario: ninguna antinomia se presenta hasta el momento en que se trata de decidir si la obligación tributaria grava -supongamos-a ciudadanos empleados o a extranjeros y apátridas desempleados. Pero, cada vez que esté en discusión la obligación tributaría de un ciudadano desempleado, comparece una antinomia. Esto sucede por la simple razón de que, aun siendo diversos los dos supuestos de hecho abstractos, existen supuestos de hecho concretos que entran dentro del campo de aplicación de ambas normas: los ciudadanos sin empleo pertenecen tanto a la clase de los ciudadanos como a la de los desempleados. En cambio, de hecho, no se presentaría ninguna antinomia si la clase de los desempleados estuviera vacía, es decir, si no existieran ciudadanos en situación de desempleo. Por tanto, puede decirse, las antinomias en abstracto dependen de la estructura conceptual del lenguaje legislativo, mientras las antinomias en concreto dependen de la estructura del mundo.

3. En tercer lugar, los conflictos entre principios son normalmente antinomias de tipo eventual, o, según la terminología de A. Ross, parcial-parcial. También en este caso parece oportuno hacer alguna precisión.

A veces, dos normas, N1 y N2, disponen consecuencias jurídicas incompatibles para dos clases de supuestos de hecho que se superponen completamente, de manera que cada supuesto de hecho concreto que entre en el campo de aplicación de N1 entrará también en el campo de aplicación de N2. Este tipo de antinomia se llama absoluta (o total-tota). Si, por ejemplo, una norma califica de lícito y otra califica de ilícito el divorcio, la antinomia será del tipo absoluto.

Otras veces, la clase de supuestos de hecho disciplinada por una de las dos normas, N1 está enteramente incluida en la (constituye una subclase de la) clase de supuestos de hecho disciplinada de forma incompatible por la otra N2 de manera que habrá supuestos de hecho que 
entran sólo en el campo de aplicación de N2, y supuestos de hecho que entran también en el campo de aplicación de Ni; el conflicto nace sólo en relación con estas últimas. Este tipo de antinomia se llama unilateral (o "total-parcial"). Si, por ejemplo, una norma califica de ilícito el aborto y otra califica de lícito el aborto terapéutico, la antinomia será del tipo unilateral.

Otras veces, las dos normas, N1 y N2, disciplinan clases de supuestos de hecho que se superponen sólo parcialmente. Así, hay supuestos de hecho disciplinados sólo por N1, supuestos de hecho disciplinados sólo por N2, y supuestos de hecho disciplinados por ambas normas: el conflicto nace solamente en relación con estos últimos. Este tipo de antinomia se llama eventual (o parcial-parcia). Si por ejemplo, una norma N1 impone un tributo a los productores de vino tinto, una segunda norma N2 atribuye la denominación de origen controlada a ciertos vinos blancos y tintos, y una tercera N3 exime del impuesto a los productores de vino con denominación de origen controlada. La antinomia entre N1 y N3 -0, si se prefiere, entre $\mathrm{N} 1$ y el combinado dispuesto por N2 y N1- será de tipo eventual.

Por consiguiente, la conclusión es que los conflictos entre principios o al menos los que se dan entre principios constitucionales no pueden ser resueltos con las mismas técnicas habitualmente usadas para resolver los conflictos entre normas. No es aplicable el criterio lex superior derogat inferiori, porque se está hablando de normas del mismo rango en la jerarquía de fuentes. Tampoco es aplicable el criterio lex posterior derogat priori, porque los principios implicados se encuentran (al menos en el caso de los principios constitucionales) estatuidos por un mismo documento normativo, $y$, en consecuencia, son coetáneos. Por último, no se puede aplicar el criterio lex specialis derogat generali, porque, cuando se trate de una antinomia del tipo eventual, no concurre entre las clases de supuestos de hecho disciplinados por los dos principios una relación de género a especie.

La técnica apropiada $-y$, por tanto, la que efectivamente se usa, en especial por los tribunales constitucionales para resolver
Ios conflictos de este tipo- es la que se conoce con el nombre de ponderación.

La ponderación de principios consiste en instituir entre los dos principios en conflicto una jerarquía axiológica móvil.

A) Una jerarquía axiológica es una relación de valor instituida [no por las mismas fuentes, sino] por el intérprete, precisamente mediante un subjetivo juicio de valor. Instituir una jerarquía axiológica consiste en atribuir a uno de los dos principios en conflicto mayor peso, es decir, mayor valor, respecto del otro. El principio dotado de mayor valor prevalece, en el sentido de que es aplicado; el principio axiológicamente inferior sucumbe - no en el sentido de que resulte inválido o abrogado, sino en el sentido de que se deja de lado.

Obsérvese que, en este contexto, ponderar no significa atemperar, conciliar o algo por el estilo, es decir, no significa hallar un punto de equilibrio, una solución "intermedia" que tenga en cuenta ambos principios en conflicto y que -de algún modo- aplique o sacrifique parcialmente a ambos. La ponderación consiste sobre todo en sacrificar o descartar un principio aplicando el otro.

B) Una jerarquía móvil, por otra parte, es una relación de valor inestable, mudable, que vale para el caso concreto, pero que podría invertirse en relación con un caso concreto diverso.

En efecto, para instituir esta relación jerárquica, el juez no sopesa el valor de dos principios en abstracto y de una vez por todas, sino que valora el posible impacto de su aplicación al caso concreto. Si el resultado que tendría en el caso concreto la aplicación del principio P1 parece más justo (o menos injusto) que el resultado que tendría la aplicación del principio P2, entonces, en el caso concreto se prescindirá del principio $\mathrm{P} 2$, mientras que en el caso concreto se aplicará el principio P1.

Pero, téngase en cuenta, en el caso concreto. Nada impide que, en caso diverso, sea la aplicación de P2 la que tenga resultados que se consideren más justos (o menos injustos) que la aplicación de P1, y que, por tanto, la relación 
jerárquica resulte invertida, aplicando P1 y prescindiendo de P2. En este sentido, pues, se trata de una jerarquía móvil: si en un caso se ha atribuido mayor peso o valor a P1, nada impide que en un caso diverso se atribuya mayor peso o valor a P2.

En consecuencia, el conflicto no se resuelve de manera estable, de una vez por todas, haciendo sin más prevalecer uno de los dos principios en litigio sobre el otro; toda solución del conflicto vale sólo para el caso concreto $y$, por tanto, la solución del conflicto en casos futuros resulta imprevisible.

Creo que es patente que esta operación comporta una doble discrecionalidad. Es discrecional la operación consistente en instituir una jerarquía de valores entre los principios implicados, y es asimismo discrecional la operación consistente en cambiar el valor relativo de tales principios a tenor de los diversos casos concretos."

\section{LA INTERPRETACIÓN. KELSEN: CONCEPTOS JURÍDICOS INDETERMINADOS}

\section{Los tipos de interpretación}

El individuo que quiere acomodar su conducta a lo que exige el orden jurídico tiene que comprender los preceptos jurídicos que quiere respetar; para ello, establece su sentido, es decir, las interpreta. La ciencia jurídica, cuando describe el derecho positivo y señala el sentido en que se deben entender las normas, debe interpretarlas. Cuando un órgano jurídico tiene que aplicar el Derecho, debe, ante todo, establecer el sentido de la norma que quiere aplicar, es decir, debe interpretarla. Se interpretan las normas no sólo cuando se produce una sentencia judicial, sino también cuando se deben producir otros actos de aplicación del Derecho. Por ejemplo, se tiene una interpretación de la Constitución por el órgano legislativo (aplicación inmediata de la Constitución), por cuanto le corresponde aplicarla a través del procedimiento legislativo.

Hay, entonces, dos tipos de interpretación del derecho: la efectuada por un órgano jurídico encargado de aplicar el derecho, y la efectuada por una persona privada o de un doctrinante del derecho. Para el presente trabajo sobre la interpretación constitucional, sólo nos detendremos en la primera de estas interpretaciones.

\section{La interpretación y los métodos de interpretación}

Los distintos métodos de interpretación, como el gramatical, el histórico, el lógico, el sistemático, el finalista, etcétera, sólo demuestran la existencia del conflicto permanente entre voluntad del creador de la norma y expresión de esa voluntad. Todos ellos llevan siempre a distintos resultados, nunca a un resultado único, "correcto". Desde el punto de vista del derecho positivo es lo mismo acoger estrictamente el tenor literal de la norma para aplicar, sin preocuparse por la voluntad del legislador, que inclinarse por la voluntad supuesta del creador de la norma, dejando de lado su tenor literal. La propia existencia de distintos métodos de interpretación de una misma norma es una prueba del hecho de que existen distintas posibilidades para su aplicación.

\section{La indeterminación del acto de aplicación del Derecho}

El acto de aplicación del Derecho es relativamente indeterminado en relación con la norma que se aplica, no sólo en cuanto al contenido del acto. Hasta la norma más meticulosa tiene que dejar al ejecutor cierta cantidad de determinaciones. Por ejemplo, si un juez da la orden de privar de libertad a una persona, el ejecutor, la policía judicial, tiene que decidir cuándo, cómo y dónde ejecuta la orden, según las circunstancias; el juez no dice cuándo (si de día o de noche), cómo (si pacífica o violentamente, ya que eso depende de la resistencia que haga quien va a ser capturado) ni dónde (si en su casa o en la casa donde se oculta el delincuente). Esta indeterminación consciente lo que busca es obtener una mayor eficacia en la aplicación de las normas jurídicas, pues si a la policía judicial se le diera la orden de que sólo puede capturar de día y 
encuentra al delincuente de noche, éste no podría ser capturado en esas circunstancias.

La indeterminación del acto de aplicación del derecho puede no serintencional; se puede deber a la ambigüedad (ambivalencia) o vaguedad de una palabra o grupo de palabras. Aquí el órgano que debe aplicar la norma se encuentra ante distintos significados posibles y, por lo mismo, ante varias interpretaciones posibles. El órgano encargado de aplicar la norma cree encontrar una discrepancia entre la expresión gramatical de la norma y la voluntad de quien la dictó. También se puede presentar la situación de indeterminación del acto jurídico que se quiere aplicar como consecuencia de que dos normas con pretensión de validez simultánea se contradigan total o parcialmente. En todos estos casos son posibles varias interpretaciones.

La indeterminación del acto de aplicación del derecho puede ser intencional, producto de la voluntad del creador de la norma y se puede referir tanto al hecho condicionante como a la consecuencia condicionada. Por ejemplo, la norma penal puede dejar al juez, en caso de determinado delito, la decisión de si aplica una u otra. También puede fijar un límite máximo y uno mínimo para la pena, dejando al juez la facultad de decidir en cada caso la sanción concreta dentro de esos parámetros.

Es un esfuerzo inútil pretender fundar "jurídicamente" una de esas posibilidades con exclusión de las otras. Que el recurso interpretativo usual del argumento a contrario y a la analogía es enteramente carente de valor ya surge suficientemente de la circunstancia de que ambos conducen a resultados contrapuestos, no existiendo criterio alguno para resolver cuándo debe recurrirse al uno o al otro. También el principio de la estimación de los intereses sólo es una fórmula, pero no una solución del problema que aquí se presenta. No da un patrón objetivo que permita cotejar entre si los intereses contrapuestos, y según el cual puedan resolverse los conflictos de intereses. En especial ese patrón no puede extraerse de la norma interpretada, o de la ley que la contiene, o de la totalidad del orden jurídico, como afirma la doctrina del cotejo de intereses. Puesto que la necesidad de una "interpretación" resulta justamente de que la norma por aplicar, o el sistema de normas, deja abiertas varias posibilidades, lo que significa, por lo tanto, que no contiene ninguna decisión sobre cuál de las interpretaciones en competencia sea la de mayor valor, con lo que deja esa determinación del rango de los intereses justamente al acto que se efectúe de producción de normas (Kelsen, 1968, p. 353).

\section{Caracterización de la interpretación hecha por un órgano de aplicación del Derecho}

La interpretación que hace un órgano encargado de aplicar el derecho se diferencia de la que hace una persona no encargada de aplicarlo (particular o la doctrina), en que, además de fijar el marco de las posibilidades de aplicación, realiza un acto de voluntad, que consiste en escoger una de esas varias posibilidades. La decisión entre esas varias posibilidades es una decisión política, no jurídica:

La pregunta de cuál sea la posibilidad "correcta", en el marco del derecho aplicable, no es, según los supuestos previos, ninguna pregunta dirigida al conocimiento del derecho positivo, no es una pregunta teórica-jurídica, sino que es un problema político. La tarea de lograr, a partir de la ley, la única sentencia correcta, el único acto administrativo correcto, es en lo esencial la misma que la de crear, dentro del marco constitucional, la única ley correcta. Así como no se puede obtener, partiendo de la Constitución, mediante interpretación, la única ley correcta, tampoco puede lograrse, a partir de la ley, por interpretación, la única sentencia correcta (Kelsen, 1968, p. 353).

\section{La interpretación entendida como un cuadro dentro del cual existen varias posibilidades}

Como consecuencia de la indeterminación querida o no de la norma, se ofrecen a la aplicación del 
derecho distintas posibilidades. Por lo mismo, todo acto de aplicación es conforme a derecho si se puede imputar a una de las posibilidades de ese marco, si se mantiene dentro de él, y sólo dejará de estar conforme a derecho si se sale de ese marco.

\section{La interpretación por valores: sus problemas}

La teoría de la interpretación que aplican los tribunales constitucionales en la protección de los derechos fundamentales refleja la sempiterna disputa entre iusnaturalismo y positivismo; entre objetivismo ético y relativismo ético; entre valores objetivos y valores relativos. Mientras el iusnaturalismo presupone la existencia de valores objetivos y universales; el positivismo sostiene la relatividad de los valores y su reconducción a contextos culturales e históricos específicos.

La adopción por parte del positivismo del principio de no hacer juicios de valor se relaciona con dos exigencias fundamentales: no confundir el ser con el deber ser, a fin de evitar la falacia naturalista o ley de Hume; y la prohibición de confundir el estudio del Derecho con su valoración a la luz de criterios extrajurídicos.

El positivismo sólo acepta la existencia de "valores internos", esto es, de aquéllos definidos por el propio creador de la constitución o la ley, pues si éste no los define le deja al aplicador de la norma la posibilidad de llenarla con sus propios juicios de valor, que pueden variar de juez a juez; esto crea inseguridad jurídica. Entre los juicios de valor internos y aquellos externos pasa la línea de confín entre ciencia del derecho y política del derecho.

[...] la aplicación de normas distintas a las normas jurídicas -las normas "superpositivas" - debe ser considerada radicalmente excluida. Se afirma, en ocasiones, que existen por encima de la Constitución de todo Estado ciertas reglas de derecho natural que deberían ser respetadas también por las autoridades estatales encargadas de la aplicación del derecho.
Se trata de principios caracterizados por la constitución o en cualquier otro grado del orden jurídico y que se deducen del contenido del derecho positivo, por vía de abstracción. Es una cosa bastante inofensiva formularlas como reglas de derecho independiente. Sin embargo, estos principios son aplicados con las normas jurídicas en las cuales son realizados y solamente en ellas. Pero si se trata de principios que no han sido traducidos en normas de derecho positivos sino que debieran serlo sólo porque son justos -si bien que los protagonistas de estos principios lo tienen ya, de manera más o menos clara, como derecho-, entonces se trata simplemente de postulados que no son jurídicamente obligatorios, que expresan, en realidad, los intereses de ciertos grupos, que formulan en dirección de ciertos órganos encargados de la creación del derecho y no únicamente los dirigen al legislador, cuyo poder para realizarlos es casi ilimitado, sino también, a los órganos subordinados que no tienen este poder más que en medida tan reducida que su función comparta una mayor parte de aplicación del derecho. Sin embargo, la jurisdicción y la administración lo tienen en la misma medida cuando conservan un poder discrecional; es decir, cuando tienen que escoger entre varias interpretaciones igualmente posibles.

Precisamente, en el hecho de que la consideración o la realización de estos principios -a los cuales no se ha podido hasta ahora, a pesar de todos los esfuerzos intentados en este sentido, dar una determinación un poco unívoca-, no tiene y no pueden tener, en el proceso de creación del derecho, por las razones antes indicadas, el carácter de una aplicación del derecho en sentido técnico, se encuentra la respuesta a la cuestión de saber si estos principios pueden ser aplicados por una jurisdicción constitucional.

$Y$ es cuando sucede de otro modo, cuando, como ocurre a veces, la misma Constitución se refiere a estos principios cuando invoca los ideales de equidad, de justicia de libertad, de igualdad, de moralidad, etcétera, sin precisar, absolutamente, lo que es necesario entender con ello. Si estas fórmulas no recubren 
nada mas que ideología política corriente, de la cual todo orden jurídico se esfuerza por ataviarse, la delegación de la equidad, de la libertad, de la igualdad, de la justicia de la moralidad, etcétera, significa únicamente, a falta de una precisión de estos valores, que el legislador, así como los órganos de ejecución de la ley, están autorizados a llenar, discrecionalmente, el ámbito que les es abandonado por la Constitución y la ley.

Las concepciones de la justicia, de la libertad, de la igualdad, de la moralidad, etcétera, difieren de tal manera, según el punto de vista de los interesados que, si el derecho positivo no consagra alguna de entre ellas, toda regla de derecho puede ser justificada por una de tantas concepciones positivas. Pero en todo caso la delegación de los valores en cuestión no significa, y no puede significar, que cuando el derecho positivo sea contrario a su concepción personal de libertad, de igualdad, etcétera, pudiera dispensarse a los órganos de creación del derecho su aplicación. Las fórmulas en cuestión, no tienen, de manera general, una gran significación. Ellas no agregan nada al estado real del derecho.

Es precisamente en el dominio del derecho constitucional, en que estas fórmulas pueden jugar un papel extremadamente peligroso. Podrían interpretarse las disposiciones de la Constitución que invitan al legislador, a conformarse con la justicia, a la equidad, a la igualdad, a la libertad, a la moralidad, etcétera, como direcciones relativas al contenido de las leyes. Evidentemente por error, puesto que sólo sería así cuando la Constitución fijara una dirección precisa, es decir, cuando la misma Constitución indicara un criterio objetivo cualquiera. Sin embargo, el límite entre estas disposiciones y las disposiciones tradicionales sobre el contenido de las leyes que se encuentran en las declaraciones de derechos individuales, se borraría fácilmente, y no es, por tanto, imposible que un tribunal constitucional, llamado a decir sobre la constitucionalidad de una ley, la anule en razón de que es injusta, siendo la justicia un principio constitucional que él debe, en consecuencia, aplicar. Pero el poder del tribunal sería tal que devendría insoportable. La concepción de la justicia de la mayoría de los jueces de este tribunal podría estar en oposición completa con la concepción de la mayoría de la población, y por tanto, con la de la mayoría del Parlamento que ha votado la ley. Es obvio que la Constitución no ha querido, al emplear una palabra tan imprecisa y equivoca como la de justicia o cualquiera otra Parecida, hacer depender la suerte de toda ley votada por el Parlamento de la buena voluntad de un colegio de jueces compuesto de una manera más o menos arbitraria, desde el punto de vista político, como sería el tribunal constitucional. Para evitar un semejante desplazamiento del poder -que la Constitución no quiere y que, políticamente es completamente contraindicado- del Parlamento a una instancia que le es extraña y que puede convertirse en el representante de fuerzas políticas diametralmente distintas de las que se expresan en el Parlamento, la Constitución debe, sobre todo si ella crea un tribunal Constitucional, abstenerse de ese genero de fraseología, y si quiere establecer principios relativos al contenido de las leyes, deberá formularlos de una manera tan precisa como sea posible (Kelsen, s.f., pp. 77-82).

\section{La interpretación de conceptos jurídicos indeterminados}

Muchos de los denominados valores no son más que conceptos jurídicos indeterminados; esto es valido tanto para el concepto de justicia, buena fe, como el de libertad, igualdad o democracia.

Con respecto a los conceptos jurídicos indeterminados, como lo sostenía Kelsen, las normas jurídicas tienen una estructura indeterminada, a veces de manera inconsciente y a veces de manera consciente. Las causas de esta indeterminación son múltiples: ambigüedad del lenguaje utilizado en las normas y la vaguedad del concepto (no se puede confundir ésta con la primera). Un concepto es ambiguo si tiene más de un significado y en el contexto que se usa se utiliza en un significado y al mismo tiempo en el otro; dicho más claramente, no se distingue 
en cuál de los tantos significados se le está usando. Para evitar este error, que da lugar a una falacia en el razonamiento, se utilizan como solución las denominadas definiciones léxico gráficas.

En cambio, un concepto es vago, no porque tenga más de un significado, sino por tener un significado preciso y porque existe una categoría de objetos a los cuales es claramente aplicable; sin embargo, en el límite existe una zona de nebulosa en la que no se sabe si a otros objetos también se aplica o no; por ejemplo, el impuesto que se aplica a las casas, ise aplica también a los carroscasa? A fin de reducir la vaguedad de un concepto se debe utilizar una definición aclaratoria, que cobije no sólo a las casas, sino también de manera expresa a los carros-casa (o que los excluye expresamente).

La definición de concepto jurídico indeterminado apunta más a los conceptos vagos que a los ambiguos. Por eso algunos han afirmado que un concepto jurídico es indeterminado sólo cuando sus límites no son bien precisos (o lo que es lo mismo, no está bien delimitado). Se distinguen dos tipos de conceptos jurídicos indeterminados:

- De experiencia, como por ejemplo, peste o casa que amenaza ruina, cuyos criterios de aplicación remiten a hechos empíricos; $y$

- Xonceptos indeterminados de valor; por ejemplo, justo precio, buena fe o democracia; cuyos criterios de aplicación se refieren a juicios de valor.

Así como se pueden tener dificultades para determinar si se está ante un problema sanitario que constituye una peste o no, se pueden tener dificultades para decir si el trato es cruel o no y si la conducta fue justa o no. Como se puede observar existen problemas adicionales para los conceptos jurídicos indeterminados de valor, ya que su discusión no versa sobre hechos, sino so- bre actitudes, lo que los hace subjetivos, pues los juicios de valor intrínsecos y los principios morales no pueden ser demostrados ni verificados, no son falsos ni verdaderos.

\section{EL PRINCIPIO DE LIBERTAD, BASE FUNDAMENTAL DE LA INTERPRETACIÓN CONSTITUCIONAL EN EL ESTADO DE DERECHO}

El tribunal constitucional, al hacer el control de constitucionalidad, debe tener siempre presente cuáles son los fundamentos del Estado social y democrático de derecho.

\section{Libertad e igualdad}

La libertad y la igualdad de todos los hombres son los fundamentos de la democracia. La libertad es el principio fundamental de la democracia: "El principio de la aristocracia es la virtud; el de la oligarquía, la riqueza, y el de la democracia, la libertad" (Aristóteles, Política, p. 182).

La democracia tiene como finalidad la libertad:

El fundamento del régimen democrático
es la libertad; es el fin a que tiende toda
democracia [...] Forzosamente tiene
que ser soberana la muchedumbre, y lo
que apruebe la mayoría, eso tiene que
ser el fin y lo justo (lo que beneficie a
la mayoría) [...] Otra es el vivir como se
quiere, ésta es el resultado de la libertad
[...] Éste es el segundo rasgo esencial
de la democracia, y de aquí vino el no
ser gobernado, si es posible por nadie,
y si no, por turno. Esta característica
contribuye a la libertad fundada en la
igualdad (Aristóteles, Política, p. 250).

Las sublevaciones tienen siempre por causa la desigualdad y los que se sublevan lo hacen buscando la igualdad (Rousseau, 1962, pp. 205206). La base en la que descansa el edificio de la libertad es la igualdad. El nexo indisoluble que existe entre libertad e igualdad fue también percibido por Rousseau al establecer la finalidad de la ley (para él la ley era la expresión de la voluntad 
general). La ley debe perseguir el mayor bien de todos y esto se logra si se aseguran dos objetivos: la libertad y la igualdad. La libertad, porque toda dependencia individual es otra tanta fuerza sustraída al cuerpo del Estado. La igualdad, porque la libertad no puede subsistir sin ella. El concepto filosófico de libertad está íntimamente relacionado con el de libertades públicas, derechos civiles, garantías sociales, etcétera.

El primer pensador que estableció esta conexión entre el aspecto filosófico y el político-social fue Hegel:

En tanto que con anterioridad a Hegel el concepto del libre albedrío era considerado sobre todo en el aspecto personal, en el plano de la libertad de los actos humanos, para Hegel incluye, a la par con el aspecto propiamente filosófico, también el aspecto político-social, y llega a ser un sinónimo del concepto de libertad en general.

"El libre albedrío es la libertad en general, y todas las otras libertades sólo son formas de éste", afirmó. En esas libertades incluye, entre otras, la libertad de palabra, la libertad política y la libertad religiosa, considerando que son modificaciones, manifestaciones especiales del concepto universal del libre albedrío (Novikov, 1984, pp. 35-36).

\section{Individuo y autoridad: dos supuestos radicalmente opuestos}

El Estado de derecho parte del supuesto de que la libertad del individuo es, en principio, ilimitada. Como consecuencia de ello, el individuo puede hacer todo aquello que no le esté expresamente prohibido por la ley. En cambio, el gobernante (la autoridad) actúa siempre con competencias que, en principio, son limitadas.

Al individuo (ciudadano) lo que no le está expresamente prohibido le está permitido. Al funcionario público, lo que no le está expresamente atribuido, le está prohibido. Al particular le basta con saber que su conducta no está prohibida para que pueda realizarla; en cambio, al gobernante no le sirve este mismo argumento, puesto que para que él pueda actuar, necesita mostrar la norma que lo faculte para actuar; si esa norma no existe, está prohibida esa actuación.

En el Estado de derecho, la posición del individuo es radicalmente opuesta a la de la autoridad. Como se parte del supuesto de que, en principio, el individuo goza de una libertad ilimitada, él puede potencialmente realizar todos los actos; el individuo puede hacer todo aquello que no le esté expresamente prohibido; en cambio, la autoridad sólo puede hacer lo que el orden jurídico le autoriza realizar. En consecuencia, es una mala técnica jurídica prohibir una conducta a un órgano del Estado, pues basta no autorizarla para que no pueda llevarla a cabo.

Este esquema fundamental de relaciones entre gobernante y gobernado del Estado de derecho es consecuencia del principio de que la libertad del hombre es, en principio ilimitada, y de que el hombre era libre antes de entrar en relaciones políticas y debe continuar siéndolo dentro de estas relaciones. Por esa misma razón, Kelsen, al estudiar el contenido de la Constitución, señala que es un error de técnica establecer en la Constitución permisiones o autorizaciones a los ciudadanos para ejercer sus derechos, pues ellos son concebidos como seres libres que no necesitan de ninguna autorización para ejercer sus libertades; lo correcto sería establecer en las constituciones las prohibiciones constitucionales, cuando se quiera limitar su libertad.

Las prohibiciones constitucionales dirigidas a los órganos del Estado tienen sentido sólo cuando previamente se ha concedido una autorización casi que ilimitada a un órgano del Estado y se quiere restringir esa autorización, especialmente, las autorizaciones concedidas al órgano legislativo. Las prohibiciones constitucionales dirigidas a los individuos tienen pleno sentido, ya que éstos, de 
no existir aquéllas, podrían realizar la conducta, ya que gozan de una libertad en principio ilimitada y estas prohibiciones son una manera de restringir esa libertad.

\section{CRÍTICA DE LOS TEST Y DE LA RAZONABILIDAD}

\section{Intensidad del test}

Se quiere reiterar que la Corte Constitucional de Colombia ha trasladado un modelo de control de constitucionalidad hecho por la Corte Suprema de los Estados Unidos a una Constitución diversa y a unas circunstancias diferentes, sin explicar las razones que le dieron origen y los problemas prácticos que con él se quisieron resolver, para aplicarlo mecánicamente a una Constitución y a una realidad distintas.

Nuestro sistema jurídico es distinto del estadounidense; nuestra Constitución, a diferencia de la de Estados Unidos, tiene definidos unos derechos como fundamentales y ordena a la Corte Constitucional guardar la integridad de la Constitución, sin hacer diferencias en el método de control ni en el tipo de ley que se controla. Nuestro parámetro constitucional -que no está en la Constitución de los Estados Unidos de Norteamérica- es la integridad de la Constitución y si la Corte no lo aplica, deja desprotegidos los derechos de los ciudadanos.

El examen de constitucionalidad de una norma no se puede, a la luz de la Constitución colombiana, realizar si se aplica lo que se denomina un test de intensidad variable, según la materia a que se refiera, de tal suerte que será leve si se trata de "materias económicas, tributarias o de política internacional", por cuanto lo que a la Corte le confía el artículo 241 de la Carta es: "la guarda de la supremacía e integridad de la Constitución", sin que se pueda establecer de manera subjetiva que en unos casos debe ser más estricta que en otros, pues lo único que ha de guiar su labor es el ejercicio de la función de control que se le atribuye por la citada norma "en los estrictos términos" que la propia Constitución le señala.

La constitucionalidad de normas sometidas a control con el concepto de intensidad del test (leve, mediano o estricto) es subjetiva y caprichosa, por lo tanto, habría que preguntarse: ¿quién determina la intensidad del test?; ipor qué a unas materias se aplicaría un test leve, a otras uno mediano y a otras uno estricto? Estos interrogantes podrían conducir a preguntar ad infinitum.

Por otra parte, si se aplica en una de esas modalidades subjetivas, ese test siempre se debería hacer así en el futuro. Eso lleva a que la Corte Constitucional "se case con la tesis de que a ciertas materias se aplique de antemano un test de intensidad determinada" que la Constitución no autoriza.

Afirmar que en materias económicas el análisis de constitucionalidad se orienta mediante "un test leve de razonabilidad" compromete a la Corte en un sentido determinado y la pone a andar por un camino que después no puede deshacer $y$, además, le impide examinar con objetividad cada caso concreto. No es verdad que todo lo que se refiere a materias económicas tenga la misma trascendencia jurídico-constitucional; en consecuencia, resulta imposible de antemano afirmar que el análisis debe ser leve en esas materias, pues, como se sabe, hay unas de mayor importancia y trascendencia que otras, aunque sean todas de contenido económico.

Con base en lo anterior, es preciso decir que no es lo mismo una ley que concede un subsidio a los veteranos de la guerra del Perú -de los cuales sobreviven muy pocas personas- que la ley que adopta el Plan de Desarrollo e inversiones públicas, para juzgarlas ambas con poco rigor, con un test leve. La dificultad se evita si, en los dos casos, se juzga aplicando sin esguinces la Constitución Política. Lo mismo sucedería con un tratado internacional, si se juzga con fundamento en la Constitución uno 
destinado al intercambio cultural entre Colombia y Venezuela, por ejemplo, que otro que estableciera la pena de muerte para quienes crucen la frontera como indocumentados. En los dos casos, aunque son diversos, la constitucionalidad se debe juzgar única y exclusivamente con aplicación de las normas previstas por la Carta en una y otra hipótesis, sin necesidad de acudir a la intensidad del test, no prevista en la Constitución.

Conviene recordar que esa técnica jurídica de la intensidad de los tests de constitucionalidad, producto de la experiencia constitucional norteamericana, permite clasificarlos de tal suerte que unos serán estrictos, otros medianos y otros leves; esto dependerá del intérprete y dejará sin resolver por qué apenas se considerarían esas tres categorías y no otras adicionales, que llevarían, por ejemplo, a un test "estrictísimo", a un test "levísimo", a uno "medio estricto" o a otro "medio leve". Para agravar la incertidumbre cabría preguntarse: ¿quién determina el test que se escoge?; ¿existen criterios objetivos para hacerlo?; ¿o más bien es el intérprete quien escoge subjetivamente un testy luego, a posteriori trata de justificarlo?, ¿y con qué fundamento constitucional?

A mi juicio, el rigor en el control sobre la constitucionalidad de los actos sometidos a ese control por decisión de la Carta Política siempre debe ser el que resulte de la confrontación de las normas inferiores con aquélla, sin que se pueda, en ningún caso, aumentar o disminuir para que quepa o no la norma causada dentro de la Constitución, según la materia a la cual ella se refiera, pues ello equivale a que la Constitución se alarga o se acorta, según convenga, tal como ocurría con el lecho de Procusto, en el cual , para que el usuario cupiera, se le estiraba o se le cercenaba, a fin de que como fuera diera la medida.

Por último, los propios autores norteamericanos como Dworkin -como se vio anteriormente- no creen en los tests ni en sus grados de intensidad.

\section{El juicio de razonabilidad}

El objeto es hacer unas reflexiones que muestren toda la problemática que existe detrás del concepto de razonabilidad. El principio de razonabilidad es un límite a la legislación, más concretamente, al órgano legislativo.

Este principio ha tenido origen en la interpretación que se ha hecho del principio de igualdad, especialmente de la regla de la igualdad, que establece que los casos iguales deben ser tratados por el legislador del mismo modo y los desiguales deben ser tratados de manera diferente. Sin embargo, esta regla de igualdad no resuelve el problema, sino que lo traslada a otro lugar, pues plantea el problema de decidir cuáles son los casos iguales -para darles igual tratamiento- y cuáles no lo son -para darles distinto tratamiento-; dicho de otra manera, cuáles distinciones se justifican y cuáles no, por lo mismo, son discriminatorias.

El principio de razonabilidad trata de dar una respuesta a esta pregunta; sin embargo, implica una contradicción lógica, ya que -como dijo Riccardo Guastini- es una respuesta tautológica, pues las distinciones hechas por el legislador deben ser razonables para no ser discriminatorias. Esto significa que para distinguir deben existir razones; razones que deben ser buenas razones, buenos argumentos, que equivalen a justificaciones. Por esa razón, Guastini señala que, según el principio de razonabilidad, una distinción es justificada cuando está justificada, y esto, desde el punto de vista lógico, es una tautología.

El principio de razonabilidad también es una fuente de las denominadas lagunas axiológicas. Se denomina laguna axiológica no a la falta de norma, porque sí existe norma, pero la norma que existe no es para el intérprete la que debería existir, sino otra diversa. No es entonces la falta de cualquier norma, sino la falta de una norma justa, es decir, 
de una norma jurídica que no existe, pero que debería existir a causa del sentido de justicia del intérprete o para la justa aplicación de una norma superior (constitucional).

Cuando el legislador trata de igual modo casos que al intérprete -de la Constitución o, más exactamente, al Tribunal Constitucional- le parecen diversos, es decir, cuando el legislador no distingue cuando debería distinguir; entonces el Tribunal Constitucional dirá que falta una norma diferenciadora (existe una laguna).

Cuando el legislador trata de modo diverso casos que al intérprete de la Constitución le parecen iguales y, en consecuencia, el legislador ha distinguido sin razón, entonces el intérprete manifestará que falta una norma igualadora; en este caso también existe laguna, ya que falta la norma que iguala y que confiere el mismo derecho.

Como se puede observar, esta técnica que, como toda técnica, es útil, no se puede recibir sin espíritu crítico, ya que encubre una serie de problemas que no se puede dejar pasar por alto y sobre los cuales se quiere llamar la atención:

- ¿Quién determina el fin perseguido?

- ¿Quién determina que ese fin es más importante que otros fines?

- Aceptando que el Estado tiene diversos fines ipor qué se privilegia un fin frente a los otros?

- ¿Qué sucede cuando un fin entra en conflicto con otro fin?

Preguntas idénticas se deben hacer ante el concepto de bien común, que es el fin que justifica la restricción de un derecho fundamental. ¿Qué es el bien común? etc. De igual forma, similares cuestionamientos surgen ante el concepto de razonabilidad:
- ¿Qué es la razonabilidad?

- ¿QQuién determina lo razonable?

- ¿Cómo se resuelve el conflicto entre razones encontradas?

- ¿Qué es lo irrazonable?

- iLo razonable es un concepto objetivo o un concepto subjetivo?;

- ¿Lo razonable es un concepto válido en todo tiempo y lugar o es un concepto histórico con unas limitaciones temporales y espaciales?

Unos pocos ejemplos demuestran cómo lo razonable es un concepto histórico. Para Aristóteles, descubridor de la lógica -las reglas del razonar correctamente, por lo que no se puede ser acusado de irracional o de ser persona que no supiera razonar- consideraba razonable que unos hombres fueran esclavos de otros hombres y que las mujeres fueran inferiores a los hombres.

La Corte Suprema de los Estados Unidos consideró durante más de 150 años que era razonable que los negros estuvieran separados de los blancos y que existiera el apartheid en las escuelas; aun después de reconocer la igualdad entre negros y blancos, se regía por el principio de "iguales, pero separados". Al comienzo, para la Corte Suprema era razonable que negros y blancos no eran iguales y después cuando los consideró iguales, era razonable que los iguales estuvieran separados y sólo hasta 1954, en una célebre sentencia, dio la razón a la familia Brown, para que los iguales no estuvieran separados. Estos dos ejemplos muestran cómo el concepto de razonabilidad debe ser sometido a crítica constante.

La interpretación por medio de valores o principios presenta dos grandes inconvenientes: primero, los valores no están previamente definidos y siempre son sujetivos. Segundo, como no existe una jerarquía de los principios, sino una escala móvil, en la 
cual en un caso de conflicto entre valores ( $\mathrm{A}$ y $\mathrm{B}$ ) puede primar un valor ( $A$ sobre $B$ ) y en otro caso puede primar el valor que antes no primó (B sobre A); no existe nunca certeza jurídica ni regla general, lo que crea inseguridad, pues nunca se sabe cómo fallará el juez y lo que es más importante el Derecho se convierte en un catálogo de casos.

Algunos argumentos de quienes defienden principios son perjudiciales; las guerras religiosas, la esclavitud, la inquisición y el totalitarismo no sólo fueron un cálculo utilitario, sino también la consecuencia de principios en los que creían algunos hombres. El peligro de los argumentos de principios es que se constituyen un principio para quien habla, pero no necesariamente para quien lo escucha y el hecho de ser elevado o definido como de principio no lo hace necesariamente bueno

La interpretación por principios o valores atenta contra uno de los valores fundamentales del Derecho, como es la seguridad jurídica, ya que estando dos valores en conflicto y no derogando el uno al otro, sino que la técnica se reduce a aplicar en ese caso concreto uno y dejar de aplicar el otro; en otro caso el que se dejó de aplicar se aplica y se deja de aplicar el que antes se aplicó. Este método crea una gran inseguridad, ya que nunca se sabe de antemano cuál de los dos valores en conflicto debe ceder ante el otro. Los ciudadanos nunca saben cuál valor primará sobre el otro, ya que no existe una escala de valores predeterminada que permita a los ciudadanos prever el fallo judicial, pues ningún valor vale más que otro.

La jurisprudencia no les permite a los ciudadanos orientarse en las decisiones judiciales ni en sus conflictos, ya que los casos anteriores pueden ser modificados en el nuevo caso dándole primacía al valor que antes no primó. La acción del tribunal constitucional se convierte en una decisión de caso por caso, sin que sea posible definir una escala permanente de valores y esto atenta contra la seguridad jurídica y lo que es más grave deja los derechos fundamentales (o no fundamentales, pero derechos al fin y al cabo) de los ciudadanos en manos de los tribunales, ya que los ciudadanos nunca no saben con certeza si la vida vale más que el libre desarrollo de la personalidad o viceversa.

Como se puede observar, el principio de razonabilidad es una máquina creadora de lagunas jurídicas, y es -hay que decirlo claramente- un instrumento de poder en manos de los tribunales constitucionales para revisar discrecionalmente las decisiones del legislador e, incluso, para suplantarlo. Precisamente, por ser un instrumento tan poderoso se requiere un uso muy prudente y es por eso que hay que mostrarlo de manera descarnada a los ciudadanos para que estén vigilantes en la defensa de sus derechos fundamentales, aun frente a su tribunal constitucional; lo que muestra una paradoja del Estado de derecho: cómo defienden los ciudadanos sus derechos frente al tribunal constitucional. Informándose sobre lo que hacen y cómo lo hacen; conociendo qué hay de verdad y qué hay de mentira o ideología sobre lo que hacen los tribunales constitucionales.

\section{REFERENCIAS}

Abbagnano, I. (1995). Diccionario de filosofía. Fondo de Cultura Económica.

Araujo, J. (1996). Teoría de la Constitución. Santafé de Bogotá: Ecoe Ediciones.

Araujo, J. (1999). Principios de Derecho Constitucional. Santafé de Bogotá: Mc Graw Hill.

Guibourg, R. (1992). Fines y medios: una aproximación a los derechos. Doxa-12.

Guasttini, R. (Sin fecha). Principios de Derecho y Discrecionalidad Judicial. 
Kelsen, H. (1969). Teoría general del derecho y del Estado. México: Editora Universidad Nacional Autónoma de México.

Kelsen, H. (1979). Teoría general del Estado (15 a edición). México: Editora Nacional.

Kelsen, H. (1981). Chi deve essere il custode della costituzione? en la Guistizia costituzionale. Milano: Edit. Giuffre.
Kelsen, H. (1986). Teoría pura del derecho. México: Publicaciones Universidad Nacional Autónoma de México.

Kelsen, H. (Sin fecha). ¿Qué es justicia? Editorial Ariel.

Wolfe, C. (1991). La transformación de la interpretación constitucional ( $1^{\text {a }}$ edición). Editorial Civitas. 